\title{
Influence of Microstructure on Laser Damage Threshold of IBS Coatings
}

\author{
BEUE: WE \\ FER $\cap$ b 1946

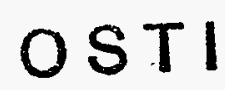

C. J. Stolz, F. Y. Génin, M. R. Kozlowksi, D. Long, R. Lalazari, Z. L. Wu, and P. K. Kuo

This paper was prepared for submittal to the Symposium on Optical Materials for High Power Lasers

Orlando, FL

October 30-November 1, 1995

January 5, 1996

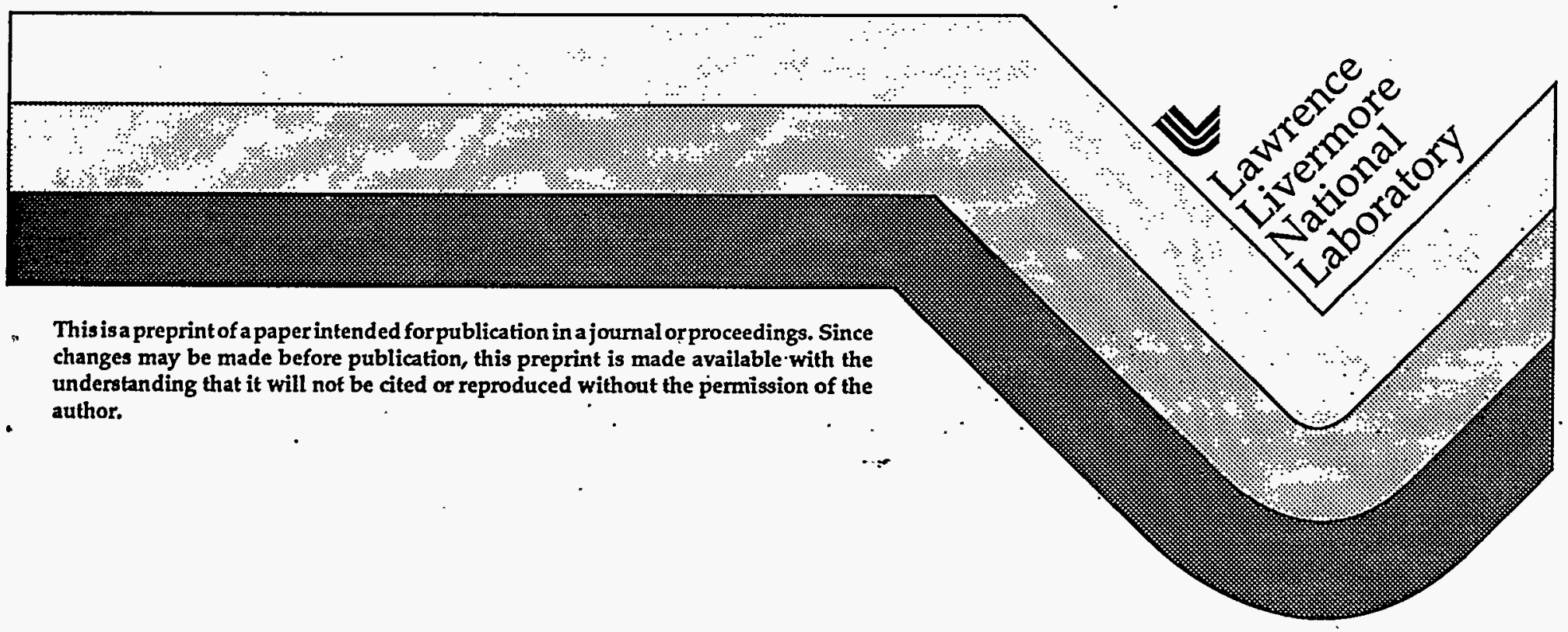

This is a preprint of a paper intended forpublication in a journal orproceedings. Since changes may be made before publication, this preprint is made available with the understanding that it will not be cited or reproduced without the permission of the author. 


\section{DISCLAIMER}

This document was prepared as an account of work sponsored by an agency of the United States Government. Neither the United States Government nor the University of California nor any of their employees, makes any warranty, express or implied, or assumes any legal liability or responsibility for the accuracy, completeness, or usefulness of any information, apparatus, product, or process disclosed, or represents that its use would not infringe privately owned rights. Reference herein to any specific commercial product, process, or service by trade name, trademark, manufacturer, or otherwise, does not necessarily constitute or imply its endorsement, recommendation, or favoring by the United States Government or the University of California. The views and opinions of authors expressed herein do not necessarily state or reflect those of the United States Government or the University of California, and shall not be used for advertising or product endorsement purposes. 
Influence of Microstructure on Laser Damage Threshold of IBS Coatings

\author{
Christopher J. Stolz, François Y. Génin, Mark R. Kozlowski \\ University of California \\ Lawrence Livermore National Laboratory \\ P. O. Box 808 , L-463 \\ Livermore, CA 94550 \\ Dale Long, Ramin Lalazari \\ Research Electro-Optics \\ 1855 South 57th Court \\ Boulder, CO 80301 \\ Z. L. Wu \\ Department of Physics and Astronomy \\ Eastern Michigan University \\ Ypsilanti, MI 48197 \\ P. K. Kuo \\ Department of Physics and Astronomy \\ Wayne State University \\ Detroit, MI 48201
}

\begin{abstract}
Multilayer coatings deposited by ion-beam sputtering with amorphous layers were found to have lower damage thresholds at $1064 \mathrm{~nm}$ than similar coatings with crystalline layers. Interestingly, at higher fluences the damage was less severe for the amorphous coatings. The magnitude of the difference in damage thresholds between the two different microstructures was strongly influenced by the size of the tested area. To better understand the microstructure effects, single layers of $\mathrm{HfO}_{2}$ with different microstructures were studied using transmission electron microscopy, ellipsometery, and a photothermal deflection technique. Since the laser damage initiated at defects, the influence of thermal diffusivity on thermal gradients in nodular defects is also presented.
\end{abstract}

Key Words: Ion beam sputtering, laser damage threshold, coating microstructure, thermal diffusivity.

\title{
1. INTRODUCTION
}

Ion-beam sputtering (IBS) coatings were developed for the laser gyro industry to meet significantly different requirements than those of fusion lasers. 'Laser gyro mirrors are small $(<25 \mathrm{~mm})$ and require low losses ( $<30 \mathrm{ppm}$ typical) and high stability with long exposures to low power laser energy. In contrast, fusion laser optics are large $(<1$ meter), have significantly reduced loss requirements ( $<5000 \mathrm{ppm}$ ) and high damage thresholds $\left(>26 \mathrm{~J} / \mathrm{cm}^{2}\right.$ at $1064 \mathrm{~nm}$ with 3-ns pulses). As part of the National Ignition Facility (NIF) coating development effort, IBS coatings are being studied to explore the possible benefits of this technology to NIF optics. As an initial step to achieving the NIF size and damage threshold requirements, the coating process is being scaled to uniformly coat a $20 \times 40 \mathrm{~cm}^{2}$ area with reduced spectral, reflected wavefront, and laser damage threshold requirements.

Brewster angle polarizer and $45^{\circ}$ high reflector (HR) coatings, designed to operate at $1064 \mathrm{~nm}$, were prepared by IBS deposition. The coatings consist of multilayers of $\mathrm{HfO}_{2}$ and $\mathrm{SiO}_{2}$ on $\mathrm{BK} 7$ substrates. The coating materials were selected since they have been consistently associated with the highest laser damage thresholds. ${ }^{2,3}$ Typically IBS coatings are amorphous which has enabled the process to generate coatings with total losses $<2 \mathrm{ppm}$. Since the refiectivity requirements of NIF polarizers is 99\% in "S" polarization and NIF mirrors is $99.5 \%$ in both polarizations, such low losses are not required, therefore, the benefits of a polycrystalline film can be investigated. By modifying the IBS deposition process, both amorphous and partially polycrystalline films can be manufactured. Coatings were deposited under five different conditions (A-E) resulting in films that were fully amorphous to almost fully crystalline respectively. 
During this development effort, amorphous coatings were found to have a lower damage threshold in contrast to previous work by Pauliwicz, et. al. ${ }^{5}$ and Hacker et. al. ${ }^{6}$ where sputtered $\mathrm{TiO}_{2} / \mathrm{SiO}_{2}$ and $\mathrm{ZrO}_{2} / \mathrm{SiO}_{2}$ coatings were found to have higher damage thresholds with reduced grain size. In both studies the pulse lengths, coating materials, and test areas differed significantly from this study. In addition, this study emphasises the influence of defects on the damage thresholds of coatings with different microstructures.

\section{DAMAGE THRESHOLD (SMALL AREA TESTS)}

The coatings were tested on the LLNL Chameleon damage test laser described elsewhere. ${ }^{7}$ This 1064-nm laser has a gaussian beam profile, 3-ns pulse length, and repetition rate of $10 \mathrm{~Hz}$. A minimum spot size of $1.0 \mathrm{~mm}$, used for all damage tests, limits the peak testing fluence to $45 \mathrm{~J} / \mathrm{cm}^{2}$. Samples are irradiated for 60 seconds, or a total of 600 shots. Two different irradiation techniques, illustrated in figure $1 \mathrm{a}$, are used to understand laser conditioning effects. ${ }^{8}$ Unconditioned, or $\mathrm{S} / 1$, measurements

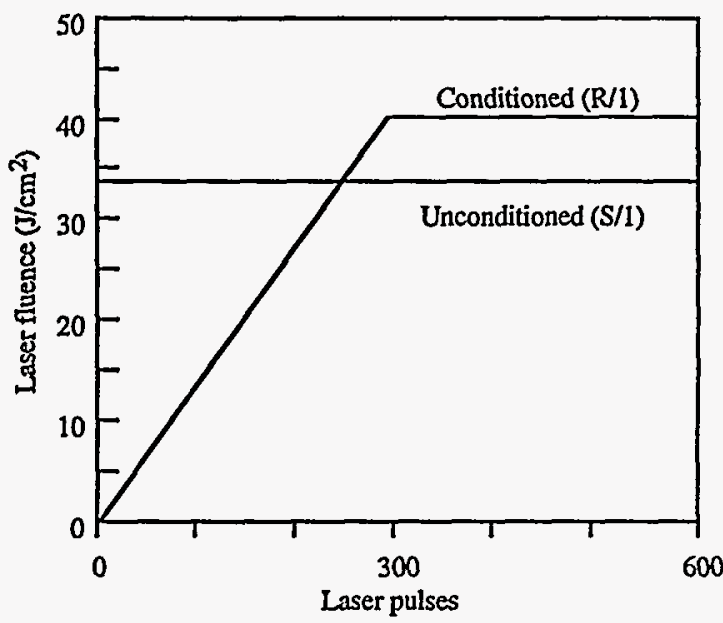

consist of irradiating the sample at a single fluence for 600 shots. Conditioned, or $\mathrm{R} / \mathrm{l}$, measurements consist of irradiating the sample at a low fluence and ramping to a higher fluence over approximately 300 shots. The fluence remains constant for the remaining 300 shots. Damage is defined as any detectable $(\sim 10 \mu \mathrm{m})$ change in the surface as viewed with dark field or Normarski microscopy at $100 x$ magnification. The damage threshold is the average of the lowest fluence for which damage occurs and the highest fluence for which no damage is detected and is below the fluence for which there is damage. The difference between these two fluences must be less than the measurement error of $\pm 15 \%$. To demonstrate repeatability of the result, a minimum of three sites must not damage within $\pm 15 \%$ of the established damage threshold as illustrated in figure $1 \mathrm{~b}$.

A summary of the damage tests are illustrated in figure 2. Although NIF HR coatings function at either polarization, the coatings were tested at "P" polarization, due to the slower decay of the standing-wave electric field and is therefore the worst case. The polarizers were tested at " $S$ " polarization since NIF polarizers will only operate at high fluence for " $S$ " polarization. For each test condition, a range

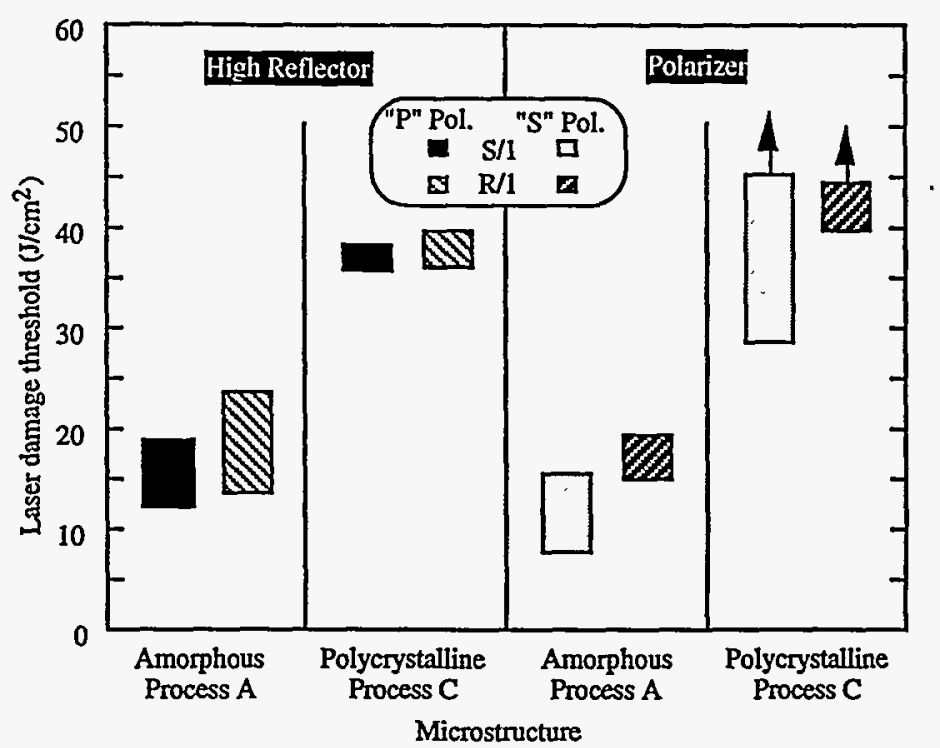

Figure 2. Laser damage threshold results from small area damage test show a strong dependence on coating microstructure.
Figure 1. (a) Irradiation method for damage testing. (b) Method for calculating damage threshold. 
of the lowest to highest damage thresholds are indicated for multiple samples. For both HR and polarizer coatings, a significantly higher damage threshold is observed for the crystalline coatings. Further analysis of the microstructure was done in an attempt to understand these findings.

\section{MICROSTRUCTURE CHARACTERIZATION}

\subsection{TEM cross sections and diffraction patterns}

Cross-sectional transmission electron microscopy (TEM) specimens were prepared using a technique described elsewhere. ${ }^{9}$ Two pieces of the substrate containing the deposited film were epoxied face-to-face, potted in a $3 \mathrm{~mm}$ diameter tube, sliced, lapped, dimpled, and finally low angle ion milled until perforation using single-sided sector ion-beam modulation conditions. Conventional bright field and dark field microscopy and selected area diffraction were performed in a JEOL 200-CX.

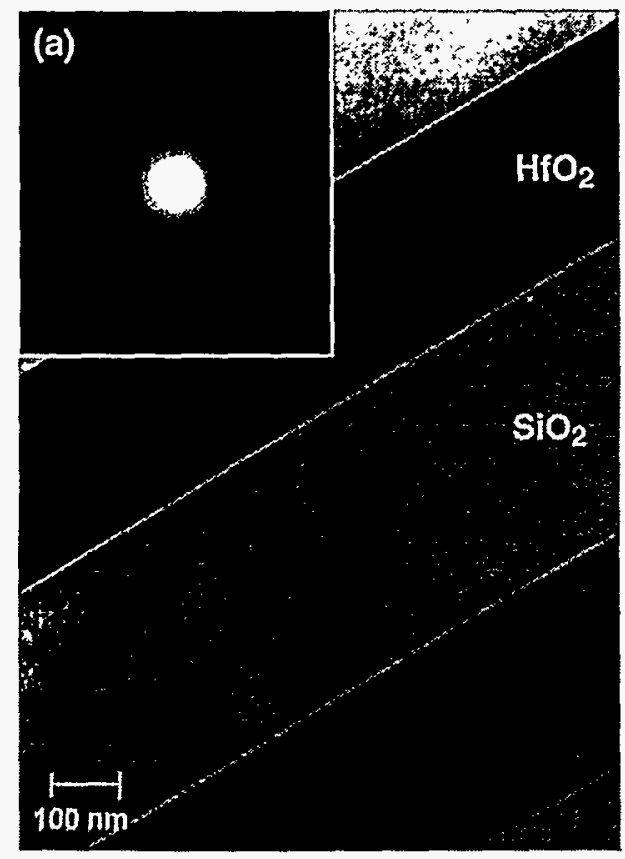

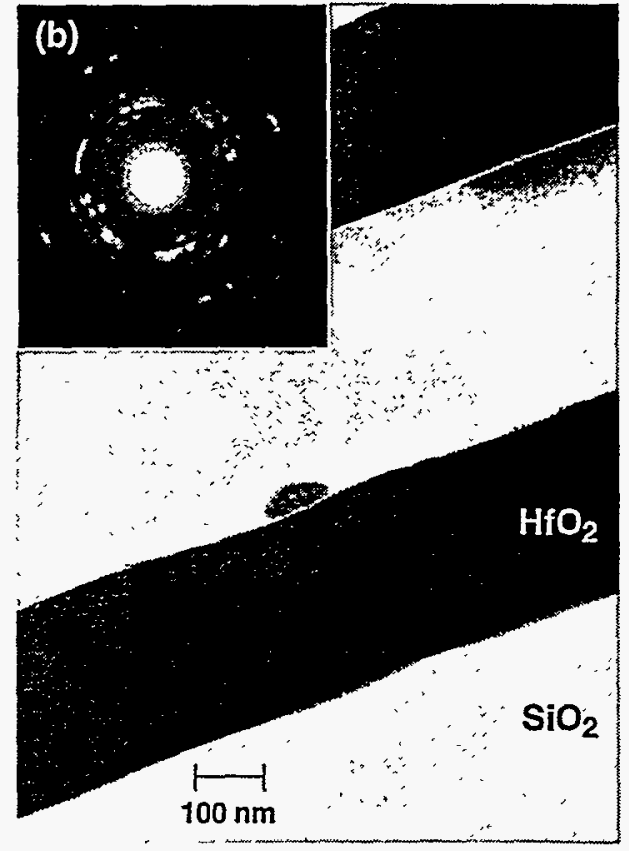

Figure 3. TEM cross sections and diffraction patterns of IBS $\mathrm{HfO}_{2} / \mathrm{SiO}_{2}$ multilayers.

(a) Amorphous microstructure. (b) Partially polycrystalline microstructure.
The TEM cross sections and diffraction patterns, shown in figure $3 \mathrm{a}$, of a multilayer deposited by process $\mathrm{A}$, indicate that the $\mathrm{HfO}_{2}$ layers are fully amorphous. Conversely, the multilayer, shown in figure $3 b$, deposited by process $\mathrm{C}$, has $\mathrm{HfO}_{2}$ layers that are amorphous and crystalline. Analysis of the diffraction spots and the diffraction ring radii verify that as the layer thickness increases, the layers undergo a sharp transistion from an amorphous to monoclinic structure. Analysis of the electron diffraction patterns does not reveal any high degree of crystal texture or a perfered crystal growth direciton. The polycrystalline nature appears more clearly in figure 4 , under dark field for the multilayer in figure $3 \mathrm{~b}$. $\mathrm{SiO}_{2}$ layers, regardless of deposition process, are always amorphous.

Single layers of $\mathrm{HfO}_{2}$ were also prepared to understand the process parameters required to achieve a higher degree of crystallization. As shown in figure 5 , amorphous to nearly fully monoclinic structures can be generated. It was also found that the substrate material had an effect on the crystalline phase of the coating. $\mathrm{HfO}_{2}$ films deposited on $\mathrm{BK} 7$ are amorphous at the substrate interface, while $\mathrm{HfO}_{2}$ films deposited on fused silica substrates have either

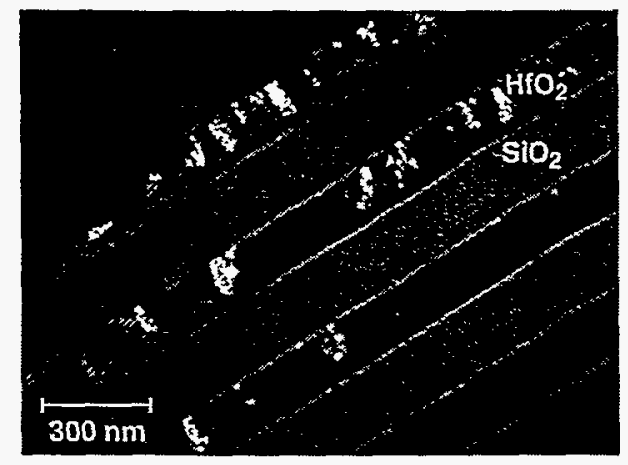

Figure 4. Dark-field TEM characterization reveals polycrystaline and amorphous structures in $\mathrm{HfO}_{2}$ layers. 
(1)

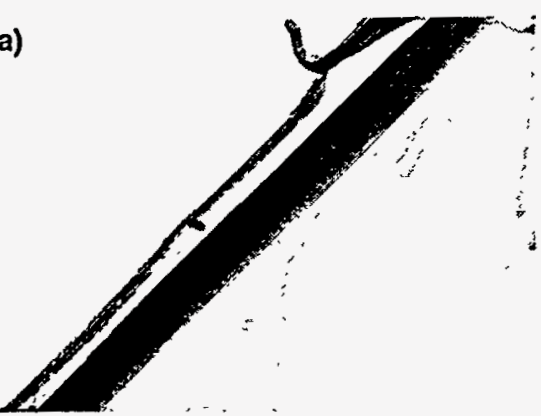

(b)

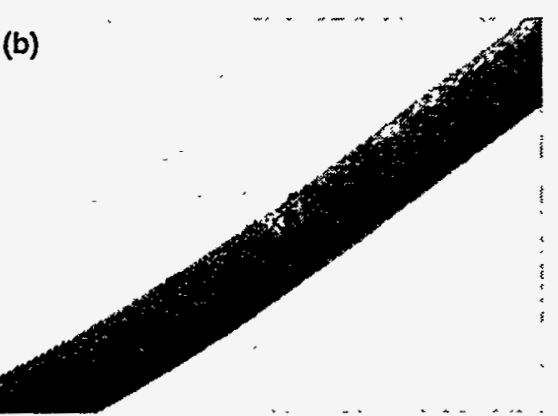

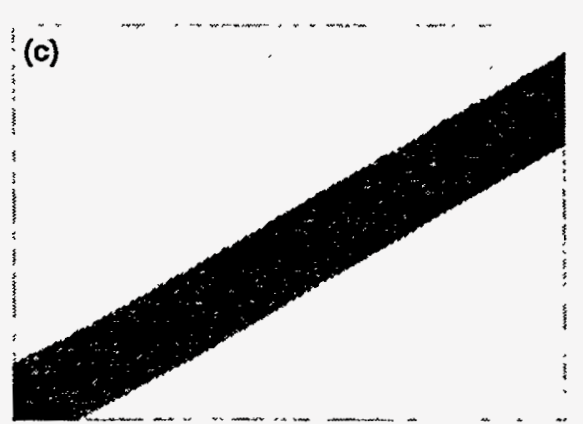

Figure 5. (a) Completely amorphous. (b) Partially polycrystalline. (c) Predominantly monoclinic phase.

amorphous or orthorhombic structures at the coating substrate interface. In both cases, there is a sharp transistion from the amorphous or orthorhombic structure to a monoclinic structure.

\subsection{Surface morphology}

To understand the relationship between of crystal structure and surface roughness, the surfaces of the amorphous and crystalline multilayer coatings were scanned using atomic force microscopy. These measurements, shown in figure 6, indicate that crystalline coatings are rougher than amorphous coating. This is consistent with the TEM cross sections that show significantly rougher interfaces for the crystalline $\mathrm{HfO}_{2}$ and amorphous $\mathrm{SiO}_{2}$ layers. Further evidence of increased surface roughness of the partially crystalline coatings is a greater amount of scattered light while viewing the sample with a high intensity light.
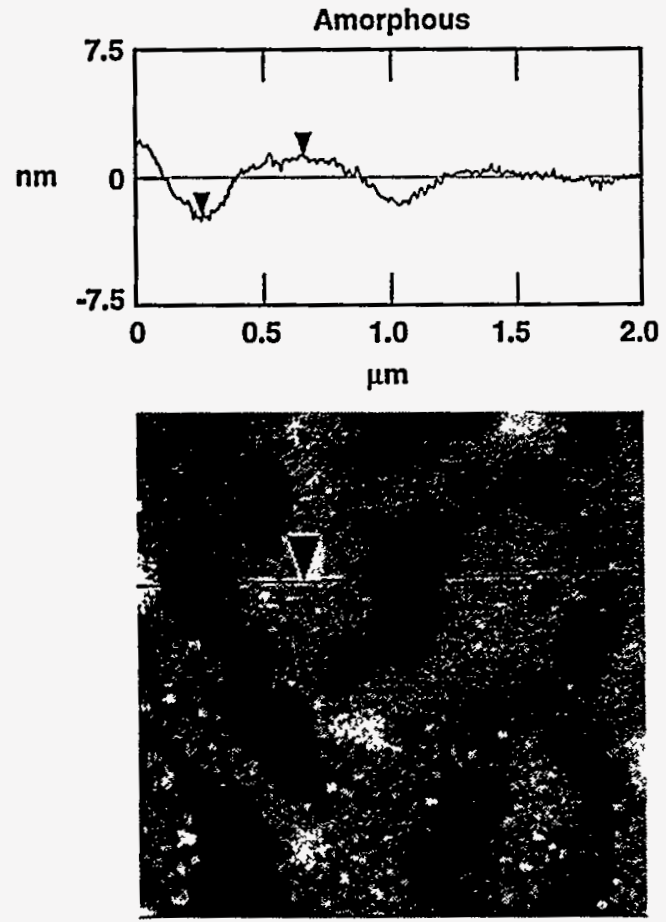

RMS $1.25 \mathrm{~nm}$
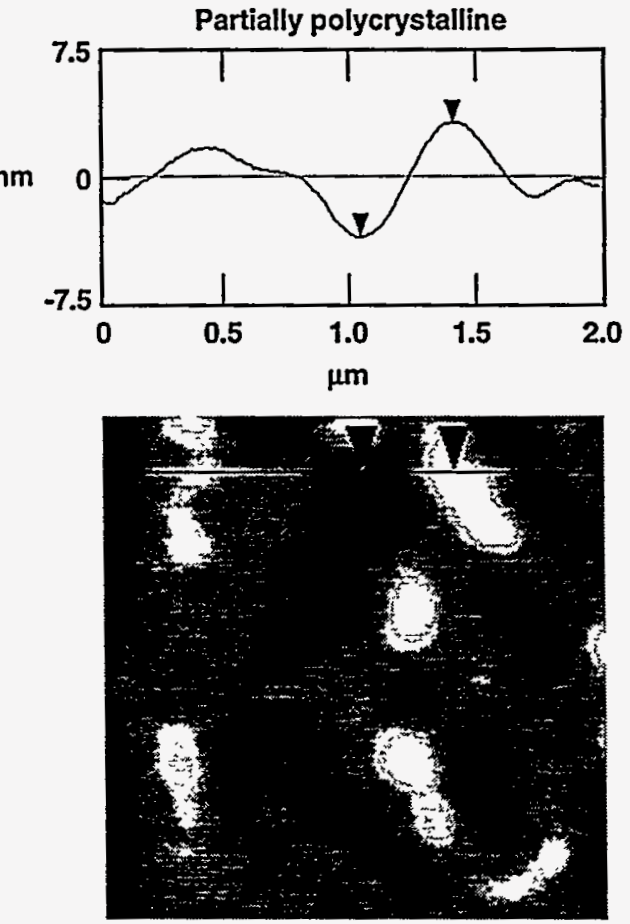

RMS $2.45 \mathrm{~nm}$
Figure 6. Coating microstructure affects surface roughness. 


\subsection{Ellipsometery}

Refractive index measurements of the $\mathrm{HfO}_{2}$ single layers were made at a wavelength of $830 \mathrm{~nm}$ on a Rudolph Research AutoEL II-NIR-3 ellipsometer. Previous attempts at measuring refractive index of $\mathrm{HfO}_{2}$ coated on fused silica substrates were unsuccessful, therefore silicon wafers, with a higher refractive index than $\mathrm{HfO}_{2}$, were included in each coating run. As illustrated in figure 7 , the refractive index increases with higher degree of crystallinity. From a coating design perspective, the greater the refractive index difference between the high and low index material, the wider the reflectance band of mirrors and polarization splitting band of polarizers. Thus the coating becomes easier to manufacture due to less critical centering error tolerances.

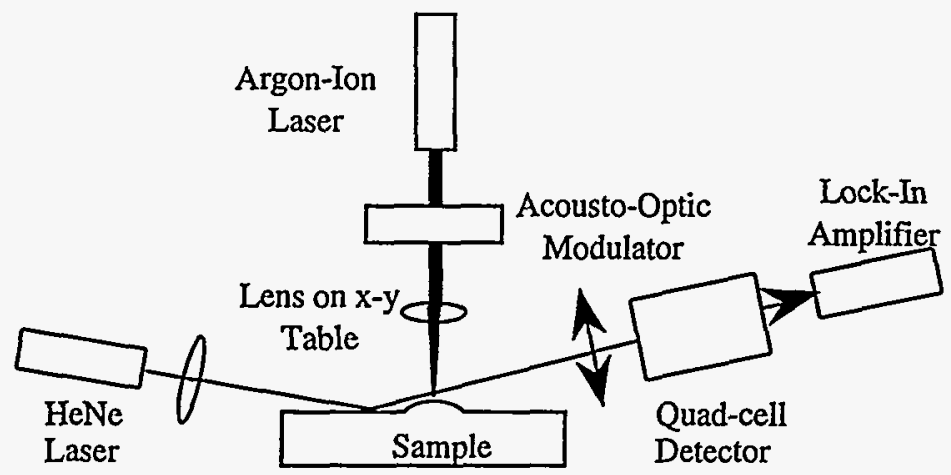

Figure 8. Schematic diagram of the mirage set up for thermal diffusivity measurements.

\subsection{Thermal diffusivity}

Thermal diffusivity measurements were performed by the mirage technique, as shown in figure 8 and described elsewhere. ${ }^{10}$ In summary, a modulated Ar laser is used as a pump beam to generate thermal waves in the coating and, hence, in the air above the coating. A HeNe probe laser skims the surface and is deflected by the time-varying gradient in the refractive index of the air (mirage effect) above the sample. A positionsensitive quad-cell detector is used to measure the deflection of the probe beam. The pump beam is scanned across the probe beam to determine the maximum deflection. Measurements are made at different modulation frequencies and fitted to theoretical prediction. A typical mirage signal is shown in figure 9. As can be seen from the data, experiment and theory agree reasonably well.

The measurements were very difficult to perform on single layers with only one quarter-wave optical thickness (QWOT) due to the small mass of the films and the small difference in thermal diffusivity between the coating and substrate. The results of thes measurements are in figure 10. A significant reduction in the signal to noise ratio was achieved with thicker films of five QWOT deposited by processes $A$ and $C$. The thermal diffusivity of the process A film is $0.0035 \mathrm{~cm}^{2} / \mathrm{s}$ and $0.0050 \mathrm{~cm}^{2} / \mathrm{s}$ for the process $\mathrm{C}$ film. Both films have amorphous $\mathrm{HfO}_{2}$ at the substrate interface. The films deposited by process $A$ have some crystalline areas at thicknesses exceeding one QWOT. The coating deposited by process $\mathrm{C}$ has a thicker crystalline region resulting in a greater percentage of crystalline to amorphous $\mathrm{HfO}_{2}$ than films of only one QWOT.

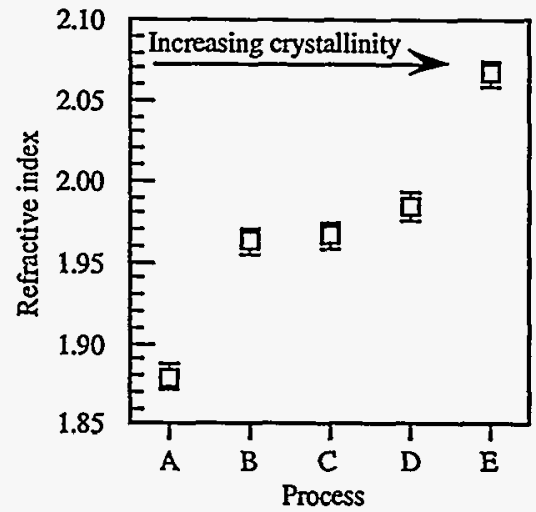

Figure 7. $\mathrm{HfO}_{2}$ refractive index

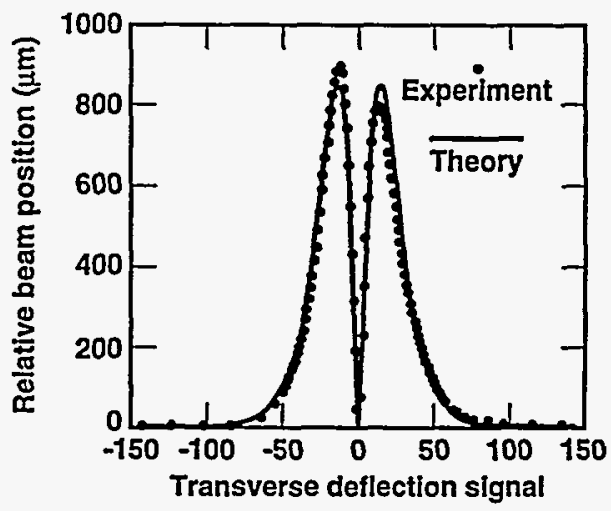

Figure 9. Typical mirage signal of amorphous multilayer coating $(f=1 \mathrm{kHz})$.

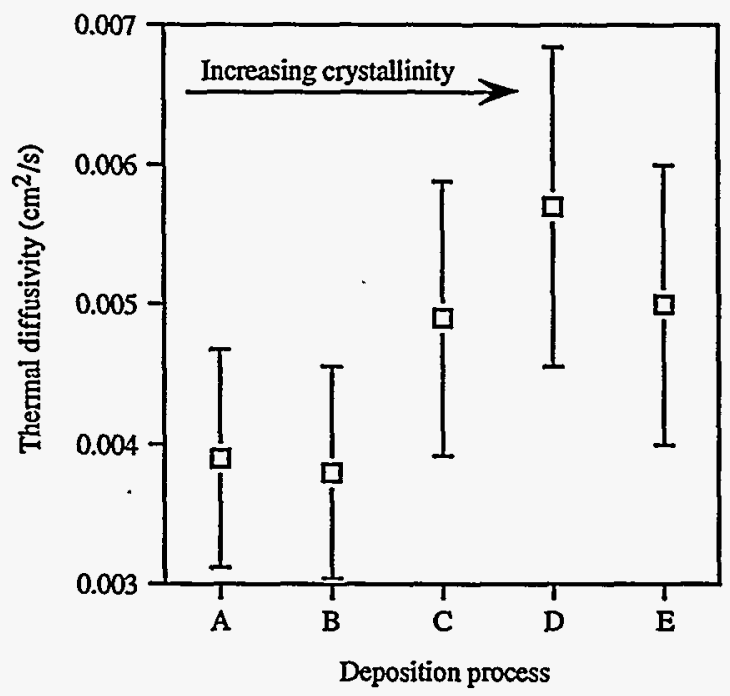

Figure 10. Thermal diffusivity results for $\mathrm{HfO}_{2}$ single layers. 
Thermal diffusivity measurements were also conducted on the $\mathrm{HfO}_{2} / \mathrm{SiO}_{2}$ multilayers shown in figures $1 \mathrm{a}$ and $\mathrm{b}$. Since the $\mathrm{SiO}_{2}$ layers remain amorphous, independent of the process, a measurement of a thick coating with the proper crystalline structures, could be made for comparison of thermal diffusivity differences. The fully amorphous coatings had an average thermal diffusivity of $0.0045 \mathrm{~cm}^{2} / \mathrm{s}$ while the partially polycrystalline coating had an average thermal diffusivity of $0.0061 \mathrm{~cm}^{2} / \mathrm{s}$. At this time, interface absorption between the different coating materials has not been measured so an absolute calculation of the thermal diffusivity is not possible. Regardless, in three different sample types, an increase in thermal diffusivity of $28-43 \%$ by crystallization of the $\mathrm{HfO}_{2}$ layers was observed.

A thermomechanical model, described elsewhere, ${ }^{11}$ was used to understand the significance of the increased thermal diffusivity. The model predicts the electric field enhancement due to nodules in the coating. The e-field enhancement is then used to calculate the temperature and associated stress gradients. The standard test case previously documented has the following assumptions: $0.73 \mu \mathrm{m}$ seed diameter, $1.97 \mu \mathrm{m}$ seed depth, and "classic" nodule shape. Two cases were run with a SiO2 thermal diffusivity of $0.01 \mathrm{~cm}^{2} / \mathrm{s}$ and and a 35\% difference in HfO2 thermal diffusivities for a 5\% reduction in peak temperature. At longer pulse lengths, thermal diffusivity would have a significantly greater effect.

\section{DAMAGE THRESHOLD (LARGE AREA TESTS)}

Typically IBS coatings have very low defect densities resulting in the irradiation of few defects during a standard damage test. Since defects do not all have the same damage threshold, the small number of irradiated defects may not yield a statistically significant result. This problemcan be solved by raster scanning the optic with a small beam over a large area. At LLNL there are two facilities capable of raster scanning including one system used for laser conditioning Beamlet laser optics up to 1 meter in size. ${ }^{12}$

The typical irradiation sequence used for a large area test is a conditioned, or $N / 1$, measurement. The sample is irradiated at a low fluence $\left(5 \mathrm{~J} / \mathrm{cm}^{2}\right.$ for these tests) over the scanned area. If no damage occurs, the sample is then rescanned at increasingly higher fluences $\left(5 \mathrm{~J} / \mathrm{cm}^{2}\right.$ increments for these tests) until damage is observed. The $90 \%$ intensity is used to calculate the minimum increment that the sample must traverse between pulses. Since the beam has a gaussian beam profile, any defect in the scanned area will be exposed to one pulse with $\geq 90 \%$ of the peak intensity of the beam and eight pulses with $\geq 1 / \mathrm{e}^{2}$ of the peak intensity. This is a useful test becauseit simulates laser conditioning of NIF production optics, and verifies the damage threshold over a more statistically significant number of coating defects.

Large area scans resulted in very different damage thresholds than the standard damage test. For both amorphous and partially polycrystalline coatings, visible changes to the surface were observed at $15 \mathrm{~J} / \mathrm{cm}^{2}$ but not at $10 \mathrm{~J} / \mathrm{cm}^{2}$. These results are consistent with the theory that defects have different damage thresholds. Although the damage thresholds measured over large areas are similar, independent of microstructure, the number of plasmas that were observed during a scan were very different as
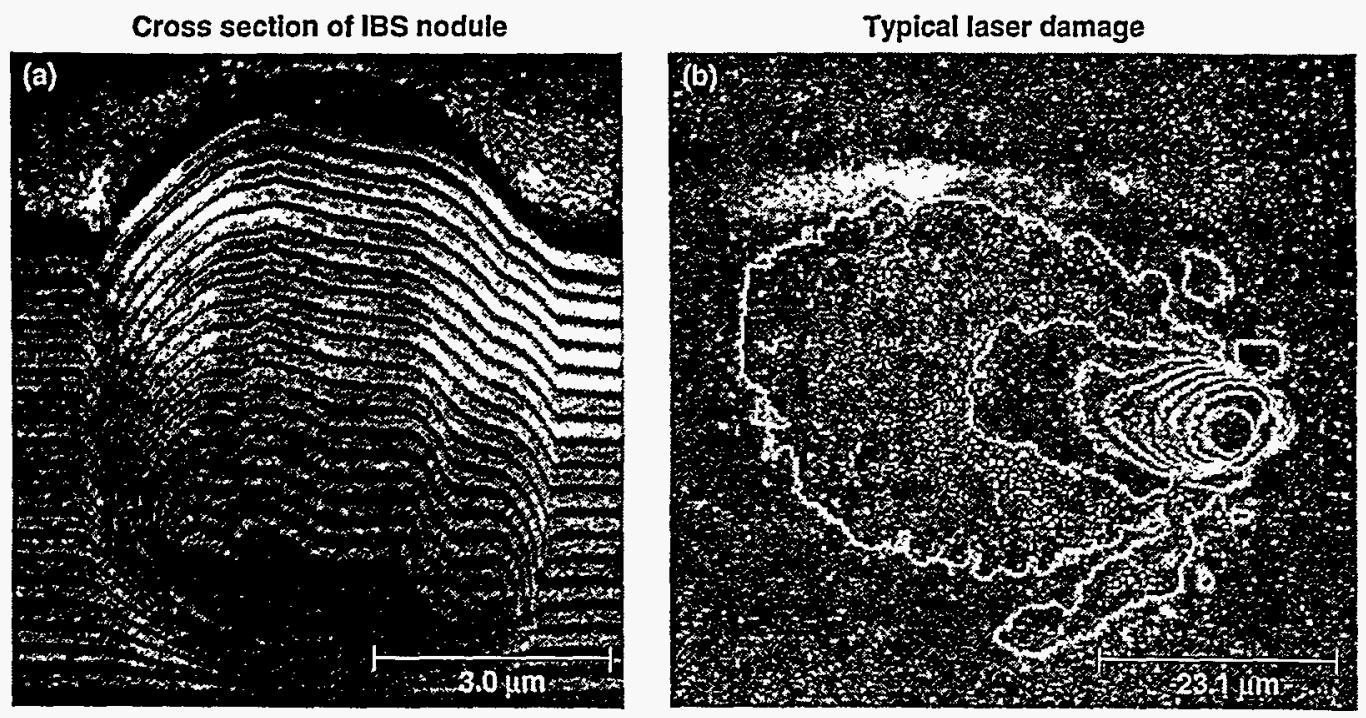

Figure 12. IBS coatings damage catastrophically at nodular defects. 
shown in table 1. A larger number of plasmas were observed at lower fluences for the amorphous coatings. Interestingly, a larger number of plasmas were observed at higher fluences for the crystalline coatings. Although plasma occurances are associated with permanent changes to the surface, multiple plasmas can occur at the same damage site so they cannot be used to determine the number of damage sites.

Table 1. Number of plasmas observed during a scan increase with fluence and varies with microstructure

\begin{tabular}{lllll}
\hline Microstructure & $5 \mathrm{~J} / \mathrm{cm}^{2}$ & $10 \mathrm{~J} / \mathrm{cm}^{2}$ & $15 \mathrm{~J} / \mathrm{cm}^{2}$ & $20 \mathrm{~J} / \mathrm{cm}^{2}$ \\
\hline Amorphous & 23 & 36 & 24 & 98 \\
\hline Partially polycrystalline & 0 & 17 & 160 & Massive damage \\
\hline
\end{tabular}

These results indicate that damage occurs at lower fluences in amorphous coatings and that damage is less severe at higher fluences. One possible explanation for this phenomenon is apparent by examining the nodules in greater detail. By cross sectioning and imaging the nodule with a focused ion-beam, the mechanical stability of the nodule can be examined. ${ }^{13}$ In the case of IBS nodules, as illustrated in figure 12a, the interface between the nodule and multilayer is very continuous, likely resulting in a rigid defect. Since laser irradiation results in nodular ejection, it is conceivable the nodules will fracture at regions other than the nodule / multilayer interface resulting in catastrophic damage as illustrated in figure 12b. Since microstructure can influence the mechanical properties of the films, it is possible that the nodular ejection occurs differently in amorphous and polycrystalline films.

\section{SUMMARY}

The microstructure influenced the properties of IBS coatings. Amorphous coatings have lower damage thresholds than polycrystalline coatings, but the damage morphology is less severe at higher fluences. A possible explanation for this behavior is different mechanical properties of the nodule and film for the different film structures. The refractive index and thermal diffusivity increased as a result of crystallization of the HfO2 layers.

Low defect densities of IBS films requires larger testing areas when using small diameter laser beams for damage testing. In the case of these samples, an insufficient number of tested defects resulted in a considerably higher measured damage threshold for the polycrystalline films than the entire surface could survive By scanning the full aperture in a manner similar to laser conditioning of large optics, an accurate damage threshold can be determined.

\section{ACKNOWLEDGMENTS}

The following individuals have contributed coatings and their expertise: Mark Wall and Jerry Britten at LLNL and Dan Buntman at Accurel Systems. This work was performed under the auspices of the US Department of Energy by Lawrence Livermore National Laboratory under contract No. W-7405-Eng-48.

\section{REFERENCES}

1. D. T. Wei and A. W. Louderback, "Method for fabricating multi-layer optical films," U.S. Patent 4142958, March 6, 1979.

2. F. Rainer, F. P. DeMarco, M. C. Staggs, M. R. Kozlowski, L. J. Atherton, and L. M. Sheehan, "Historical perspective on fifteen years of laser damage thresholds atLLNL," in Laser-Induced Damage in Optical Materials: 1993, H.E. Bennett, L. L. Chase, A. H. Guenther, B. E. Newnam and M. J. Soileau, Eds., Proc. Soc. Photo-Opt Instrum. Eng. 2114, 9-24 (1993).

3. C. J. Stolz and J. R. Taylor, "Damage threshold study of ion beam sputtered coatings for a visible high-repetition laser at LLNL," in Laser-Induced Damage in Optical Materials: 1992, H. E. Bennett, L. L. Chase, A. H. Guenther, B. E. Newnam and M. J. Soileau, Eds., Proc. Soc. Photo-Opt Instrum. Eng. 1848, 182-190 (1992).

4. R. Lalezari, G. Rempe, R. J. Thompson, and H. J. Kimble, "Measurement of ultralow losses in dielectric mirrors," in Optical Interference Coatings Technical Digest 1992, (Optical Society of America, Washington, D.C.), Vol. 15, 331-333 (1992). 
5. W. T. Pawlewicz, R. Busch, D. D. Hays, P. M. Martin, and N. Laegreid, "Reactively sputtered optical coatings for use at $1064 \mathrm{~nm}$," in Laser-Induced Damage in Optical Materials: 1979, H. E. Bennett, A. J. Glass, A. H. Guenther, and B. E. Newnam, Eds., NBS Spec. Publ. 568, 359-374 (1979).

6. E. Hacker, H. Lauth, P. Weißbrodt, R. Wolf, "Structural influences on the laser damage thresholds of oxide coatings," in Thin Films for Optical Systems, K. H. Guenther, Ed., Proc. Soc. Photo-Opt Instrum. Eng. 1782, 447-458 (1992).

7. A. J. Morgan, F. Rainer, F. P. DeMarco, F. P. Gonzales, M. R. Kozlowski, and M. C. Staggs, "Expanded damage test facilities at LLNL," in Laser-Induced Damage in Optical Materials: 1989, H. E. Bennett, L. L. Chase, A. H. Guenther, B. E. Newnam and M. J. Soileau, Eds., NIST Spec. Publ. 801, Proc. Soc. Photo-Opt Instrum. Eng. 1438, $47-57$ (1989).

8. L. Sheehan, M. R. Kozlowski, and C. J. Stolz, "Application of laser conditioning to increase the damage threshold of $\mathrm{HfO}_{2}$ ! $\mathrm{SiO}_{2}$ multilayer coatings over large areas," Appl. Opt., to be published.

9. R. Alani, R. G. Harper and P. R. Swann, "Ion thinning of TEM cross sections under beam switching control," Proceeding from the 50th Meeting of the Electron Microscopy, Soc. of America, G.W. Bailey ed., San Francisco Press, S.F., CA, pp. 394-5 (1992).

10 Z. L. Wu, P. K. Kuo, L. Wei, S. L. Gu, R. L. Thomas, "Photothermal characterization of optical thin films," Thin Solid Films 236, p. 191-198 (1993).

11. R. H. Sawicki, C. C Shang, and T. L. Swatlowski, "Failure characterization of nodular defects in multi-layer dielectric coatings," in Laser-Induced Damage in Optical Materials: 1994, H. E. Bennett, A. H. Guenther, M. R. Kozlowski, B. E. Newnam, and M. J. Soileau, eds., Proc. Soc. Photo-Opt Instrum. Eng. 2428, 333-342 (1994).

12. L. M. Sheehan, M. R. Kozlowski,F. Rainer, M. C. Staggs, "Large area conditioning of optics for high-power laser systems," in Laser-Induced Damage in Optical Materials: 1993, H. E. Bennett, A. H. Guenther, L. L. Chase, B. E. Newnam, and M. J. Soileau, eds., Proc. Soc. Photo-Opt Instrum. Eng. 2114, 333-342 (1993).

13. C. J. Stolz, R. J. Tench, M. R. Kozlowski, and A. Fornier, "A comparison of nodular defect seed geometeries from different deposition techniques," in Laser-Induced Damage in Optical Materials: 1995, H. E. Bennet, A. H. Guenther, M. R. Kozlowski, B. E. Newnam, and M. J. Soileau, eds., Proc. Soc. Photo-Opt Instrum. Eng., 2714, to be published. 